\title{
Do the European League Against Rheumatism (EULAR) Sjögren's syndrome outcome measures correlate with impaired quality of life, fatigue, anxiety and depression in primary Sjögren's syndrome?
}

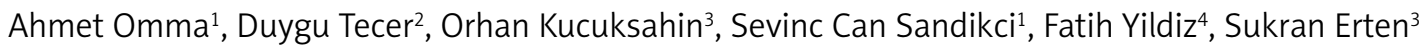

\author{
${ }^{1}$ Department of Rheumatology, Ankara Numune Training and Research Hospital, \\ Ankara, Turkey \\ 2Department of Rheumatology, Sanlıurfa Mehmet Akif Inan Training and Research \\ Hospital, Şanlıurfa, Turkey \\ ${ }^{3}$ Division of Rheumatology, Internal Medicine, Yildirim Beyazit University, Ankara, \\ Turkey \\ ${ }^{4}$ Department of Rheumatology, Van Training and Research Hospital, Van, Turkey
}

Submitted: 16 July 2017

Accepted: 31 August 2017

Arch Med Sci 2018; 14, 4: 830-837

DOI: https://doi.org/10.5114/aoms.2017.70300

Copyright @ 2017 Termedia \& Banach

\begin{abstract}
Introduction: The aim of the study was to investigate whether there is a relationship between the European League Against Rheumatism (EULAR) outcome measures and quality of life (QoL), fatigue, anxiety and depression in patients with pSS and to define determinants which could affect quality of life.

Material and methods: The study included 105 pSS patients and 72 age/ sex-matched healthy controls (HCs). Cross-sectional clinical data were collected, including the Hospital Anxiety and Depression Scale (HADS), the Multidimensional Assessment of Fatigue (MAF) scale, the Short Form (SF-36), EULAR Sjögren's syndrome disease activity index (ESSDAI) and EULAR Sjögren's syndrome patient reported index (ESSPRI).

Results: The SF-36 scores were significantly lower and anxiety, depression and fatigue scores were significantly higher in the pSS group than in the control group (all $p$-value $<0.05$ ). ESSDAl was negatively correlated with SF-36 scores and positively with MAF. ESSPRI was negatively correlated with SF-36 scores except for the mental health subdimension, and a positive correlation was determined with MAF, HADS-A and HADS-D. Multiple linear regression analysis revealed that HADS-A, HADS-D, MAF, ESSPRI and ESSDAI were associated with most SF-36 subscales.

Conclusions: The results of this study provide further evidence supporting the use of ESSDAI and ESSPRI in daily practice. Quality of life was diminished in patients with pSS and was associated with different symptoms. This should be taken into account when managing patients with pSS.
\end{abstract}

Key words: Sjögren's syndrome, quality of life, depression, anxiety, EULAR Sjögren's syndrome disease activity index, EULAR Sjögren's syndrome patient reported index.

\section{Introduction}

Sjögren's syndrome (SS) is a systemic autoimmune disease characterized by lymphocytic infiltration of the exocrine glands, predominantly the salivary and lacrimal glands [1]. Global worldwide prevalence is

\author{
Corresponding author: \\ Ahmet Omma MD \\ Department of Rheumatology \\ Ankara Numune Training \\ and Research Hospital \\ Ankara 06230, Turkey \\ Phone: +90 5052651083 \\ Fax: +903123103460 \\ E-mail: ahmetomma@ \\ hotmail.com
}


$0.06 \%$ and it predominantly affects females [2]. Oral and ocular dryness are primary clinical features which are caused by functional impairment of salivary and lacrimal glands. However, extra-glandular involvement may develop during disease progression and most patients complain of subjective symptoms such as arthralgia, myalgia and fatigue [3, 4]. In addition, several psychological disorders such as anxiety and depression are more prevalent in pSS patients than in the healthy controls [5-7]. Sjögren's syndrome is associated with working disability, general discomfort and decreased health-related quality of life (HRQOL) [8-12]. As treatment of SS is symptom oriented, HRQOL assessment is important to be able to understand the disease activity, and select the appropriate therapy [13].

The European League Against Rheumatism (EULAR) SS study group recently developed two major outcome tools to measure disease activity and patient reported symptoms: the EULAR Sjögren's syndrome disease activity index (ESSDAI) for systemic features and severity and the EULAR Sjögren's syndrome patient reported index (ESSPRI) for the measurement of patients' symptoms [14, 15]. These two instruments have been validated and shown to be sensitive to change [16].

There are various studies in the literature that have focused on fatigue, anxiety, depression, oral HRQOL and general HRQOL $[12,13,17,18]$. However, to the best of our knowledge, there are very few studies investigating the relationship between the pSS specific outcome measures (ESSPRI and ESSDAI) and HRQOL $[19,20]$. The aim of this study was to investigate whether there is a relationship between the EULAR outcome measures and quality of life (QoL), fatigue, anxiety and depression in patients with primary Sjögren's syndrome (pSS) and to define determinants which could affect quality of life.

\section{Material and methods}

\section{Patients}

A total of 105 consecutive pSS patients who met the 2002 American-European Consensus Group (AECG) criteria for diagnosing PSS [21] and were being followed up at the rheumatology outpatient clinics of 3 hospitals in Turkey were enrolled in this multicentre, cross-sectional study. The control group was formed of 72 age- and gender-matched healthy individuals. Exclusion criteria were patients with known psychiatric disease, fibromyalgia, comorbid chronic diseases, such as hyperthyroidism, hypothyroidism, diabetes mellitus, and malignancies, age $<18$ years or inability to give written informed consent. The statistical power was set to be $95 \%$ and the type 1 error rate was set to be $5 \%$. According to the results of the analysis, the sample size for each group to be suitable for analysis was 71 individuals.

The study was approved by the Ethics Committee of Yildirim Beyazit University Medical School and written informed consent was obtained from all participants according to the principles of the Helsinki Declaration. The demographic, clinical and laboratory data of the patients were recorded.

Fatigue was assessed using the Multidimensional Assessment of Fatigue scale (MAF). This self-reported questionnaire contains 16 items and measures four dimensions of fatigue: severity, distress, timing and degree of interference with daily living activities. The MAF score ranges from 0 to 50 and higher scores indicate higher levels of fatigue [22].

Anxiety and depression were assessed with the Hospital Anxiety and Depression Scale (HADS). This self-evaluation questionnaire consists of 2 subscales: anxiety (HADS-A) and depression (HADS-D). Both subscales contain 7 items and each item is scored from 0 to 3 . HADS scores of 8-10 define possible, scores of 11-14 define probable and scores of 15-21 define extreme cases of depression and anxiety [23].

Quality of life was assessed with a validated Turkish translation of the 36-item Short Form (SF-36) [24]. The SF-36 is a questionnaire for self-evaluation of the prior 1 month. It consists of eight health-related domains including physical functioning (PF, 10 items), role-physical (RP, 4 items), bodily pain (BP, 2 items), general health (GH, 5 items), vitality (VT, 4 items), social functioning (SF, 2 items), mental health ( $\mathrm{MH}, 5$ items), and role-emotional (RE, 3 items). Based on these separate domains, physical (PCS) and mental component summary scores (MCS) are calculated. Each domain and summary score ranges from 0 to 100, with higher scores indicating a better quality of life [25].

The ESSPRI is a self-evaluation index for measuring symptoms including pain, fatigue and dryness. Each symptom was measured with a single 0 (no symptoms) to 10 (severe symptoms) numerical scale and the final ESSPRI score is calculated by averaging these domains with a maximum severity score of 10 . Scores of $<5$ indicate low disease activity and scores of $\geq 5$ indicate high disease activity $[15,26]$.

The EULAR SS disease activity index (ESSDAI) is a physician-based assessment of the systemic features and severity of the disease and includes 12 domains (constitutional, lymphadenopathy, glandular, articular, cutaneous, respiratory, renal, muscular, peripheral nervous system, central nervous system, hematological, biological). ESSDAI ranges from 0 to 123 . ESSDAI $<5$ is defined as low disease activity, $5 \leq$ ESSDAI $\leq 13$ is defined 
Table I. Demographic and clinical characteristics of the pSS patients $(n=105)$

\begin{tabular}{|c|c|}
\hline Variables & Result \\
\hline Age [years] & $44 \pm 10.5$ \\
\hline Gender (female) & $97(92.4 \%)$ \\
\hline Age at time of diagnosis [years] & $41.5 \pm 10.0$ \\
\hline Disease duration [years] & $2.1 \pm 1.8$ \\
\hline Ocular symptoms & 99 (94.2\%) \\
\hline Oral symptoms & $96(91.4 \%)$ \\
\hline Schirmer test $\leq 5 \mathrm{~mm} / 5 \mathrm{~min}$ & $87(82.8 \%)$ \\
\hline $\begin{array}{l}\text { Positive salivary gland biopsy } \\
\text { (focus score } \geq 1 \text { ) }\end{array}$ & $93 / 81(87.1 \%)$ \\
\hline \multicolumn{2}{|l|}{ Autoantibodies: } \\
\hline Anti-Ro (SSA) & $77 / 100(77 \%)$ \\
\hline Anti-La (SSB) & $51 / 100(51 \%)$ \\
\hline ANA titer $>1 / 160$ & $83 / 103(80.6 \%)$ \\
\hline RF & $37 / 102(36.3 \%)$ \\
\hline CRP $[\mathrm{mg} / \mathrm{l}]$ & $3.4(1-3.9)$ \\
\hline ESR $[\mathrm{mm}$ in first $\mathrm{h}]$ & $20(12-34)$ \\
\hline \multicolumn{2}{|l|}{ Disease activity indexes: } \\
\hline ESSDAI & $5(2-9.5)$ \\
\hline ESSPRI & $4.6(3-6)$ \\
\hline \multicolumn{2}{|l|}{ Current treatment: } \\
\hline Corticosteroids & $26(24.7 \%)$ \\
\hline Hydroxychloroquine & $85(80.9 \%)$ \\
\hline Azathioprine & $7(6.6 \%)$ \\
\hline Methotrexate & $15(14.2 \%)$ \\
\hline Rituximab & $5(4.7 \%)$ \\
\hline Pilocarpine & $10(9.5 \%)$ \\
\hline Lachrymal substitute & $80(76 \%)$ \\
\hline Non-steroidal anti-inflammatory drug & $40(38 \%)$ \\
\hline Without treatment & $9(8.5 \%)$ \\
\hline
\end{tabular}

Results are expressed as median (IQR)], mean $\pm S D$ or number (\%), where appropriate. ANA - antinuclear antibodies, RF - rheumatoid factor, CRP - C-reactive protein, ESR - erythrocyte sedimentation rate, ESSDAI - EULAR Sjögren's syndrome disease activity index, ESSPRI - EULAR Sjögren's syndrome patient reported index, EULAR - European League Against Rheumatism.

as moderate disease activity and ESSDAI $\geq 14$ is defined as high disease activity $[14,26]$.

\section{Statistical analysis}

All data were analyzed using the Statistical Package for Social Sciences (SPSS Inc., Chicago, IL, USA) 16.0 program for Windows. The variables were investigated using visual and analytical methods to determine whether they were normally distributed. Normally distributed continuous values were expressed as mean \pm standard deviation (SD) and categorical variables as number and percentage. Non-normally distributed parameters were reported as median values with inter-quartile range (IQR) $\left(25^{\text {th }}\right.$ and $75^{\text {th }}$ percentiles). Student's t-test was used for comparison of normally distributed data, and the Mann-Whitney $U$ test, Wilcoxon rank test and Kruskal-Wallis test were used for comparison of non-normally distributed data. The $\chi^{2}$ test was used for categorical variables. Pearson's correlation coefficient and Spearman's correlation coefficient were used to evaluate the linear relationship between the predictive variables. A value of $p<0.05$ was considered statistically significant. Multivariate linear regression analysis using the stepwise method was performed to determine the variables independently associated with SF-36 scores.

\section{Results}

The demographic and clinical features of pSS patients are shown in Table I. Forty-nine (46.7\%) patients had low disease activity (ESSDAI < 5), 45 (42.9\%) had moderate disease activity $(5 \leq \mathrm{ESSDAI} \leq 13)$, and 11 (10.5\%) had high disease activity (ESSDAI $\geq 14$ ). Fifty-five (52.4\%) patients had ESSPRI $<5$ and 50 (47.6\%) had ESSPRI $\geq 5$.

Age, gender, depression, anxiety, fatigue scores, SF-36 summary scores (PCS, MCS) and laboratory parameters of the patients and the healthy controls are presented in Table II. HADS-D $(p=0.002)$, HADS-A $(p<0.001), \operatorname{MAF}(p=0.013)$ scores and erythrocyte sedimentation rate (ESR) $(p<0.001)$ were significantly higher in pSS patients than in the control group, while SF-36 summary scores $((\mathrm{PCS}, \mathrm{MCS})(p=0.01, p<0.001))$ were lower than those of the control group. In the assessment of SF-36 subgroup scores, all items, particularly role-physical (RP) and role-emotional, were observed to be statistically lower in pSS patients than in the control group $((p=0.006)$ for vitality, $(p<0.001)$ for items other than vitality) (Figure 1). Of the 105 pSS patients, $17.1 \%$ were scored as possible, $11.4 \%$ as probable and $1 \%$ as extreme cases of depression and $23.8 \%$ were scored as possible, $15.2 \%$ as probable and $5.7 \%$ as extreme cases of anxiety. If the cut-off value was considered as 8 in HADS, anxiety was found to be significantly higher in pSS patients than in the control group (47 (44.8\%) vs. 21 (38.4\%), $p=0.036)$. The frequency of depression was higher in pSS patients (31 (29.5\%) vs. $17(23.6 \%)$ ), but the difference was not statistically significant $(p=0.385)$.

The SF-36, HADS-D, HADS-A and MAF scores of the pSS patients according to disease activity 
Table II. Age, gender, depression (HADS-D), anxiety (HADS-A), fatigue (MAF), SF-36 summary scores (PCS, MCS) and laboratory parameters of pSS patients and $\mathrm{HCS}$

\begin{tabular}{|lccc|}
\hline Variables & pSS $(n=105)$ & HC $(n=72)$ & $P$-value \\
\hline Age [years] & $44 \pm 10.5$ & $44.3 \pm 6.9$ & NS \\
\hline Gender (F/M) & $97 / 8$ & $62 / 10$ & NS \\
\hline HADS-D & $6.7 \pm 2.8$ & $5.1 \pm 3.5$ & 0.002 \\
\hline HADS-A & $7.6 \pm 3.6$ & $5.4 \pm 3.3$ & $<0.001$ \\
\hline MAF & $21.7 \pm 9.1$ & $18.5 \pm 7.3$ & 0.013 \\
\hline PCS & $42.6 \pm 5.5$ & $47.1 \pm 5.8$ & 0.01 \\
\hline MCS & $40.0 \pm 6.6$ & $48.8 \pm 7.9$ & $<0.001$ \\
\hline ESR $[\mathrm{mm} / \mathrm{h}]$ & $20(12-33.5)$ & $8(5-12.7)$ & $<0.001$ \\
\hline CRP $[\mathrm{mg} / \mathrm{l}]$ & $3.4(1-3.5)$ & $2(1-4)$ & NS \\
\hline
\end{tabular}

ESR and CRP are shown as median values (IQR). Other variables are stated as mean $\pm S D$. NS - non-significant, HADS-D - Hospital Anxiety and Depression Scale-depression, HADS-A - Hospital Anxiety and Depression Scale-anxiety, MAF - Multidimensional Assessment of Fatigue, PCS - physical component summary scores, MCS - mental component summary scores, ESR - erythrocyte sedimentation rate, $C R P-C$-reactive protein.

are shown in Table III. When the disease activity was assessed with ESSDAl, except $\mathrm{MH}$ all the SF-36 scores of patients with low disease activity were significantly higher than those of patients with moderate and high disease activity. Only the BP, GH, SF, PCS and MCS scores of patients with moderate disease activity were significantly higher than those of patients with high disease activity. Patients with higher ESSDAI scores tended to have higher HADS-A, HADS-D and MAF scores without reaching statistical significance. According to the ESSPRI, except SF and MH, all SF-36 scores were significantly lower and HADS-A, HADS-D and MAF scores were significantly higher in the active group.

In correlation analysis, a positive correlation between ESSDAI and ESSPRI was detected $(r=0.31$, $p<0.001)$. Correlation analysis of pSS patients between SF-36 scores, fatigue, anxiety, depression and EULAR Sjögren's syndrome outcome measures is shown in Table IV. ESSDAI was positively correlated with fatigue score $(r=0.26$, $p=0.003)$ and negatively correlated with PCS and MCS scores $(r=-0.32, p<0.001, r=-0.50$, $p<0.001$ respectively). ESSPRI showed a positive correlation with fatigue, anxiety and depression $(r=0.80, r=0.58, r=0.49$ all $p<0.001$ respectively) and a negative correlation with PCS and MCS $(r=-0.69, r=-0.26$ and all $p<0.001$ respectively). The MAF score was positively correlated with HADS-A and HADS-D scores $(r=0.57, p<0.001$, $r=0.50, p<0.001$, respectively). The HADS-A score was positively correlated with the HADS-D score $(r=0.62, p<0.001)$.

As summarized in Table V, ESSDAI in the pSS group was an independent determinant of all

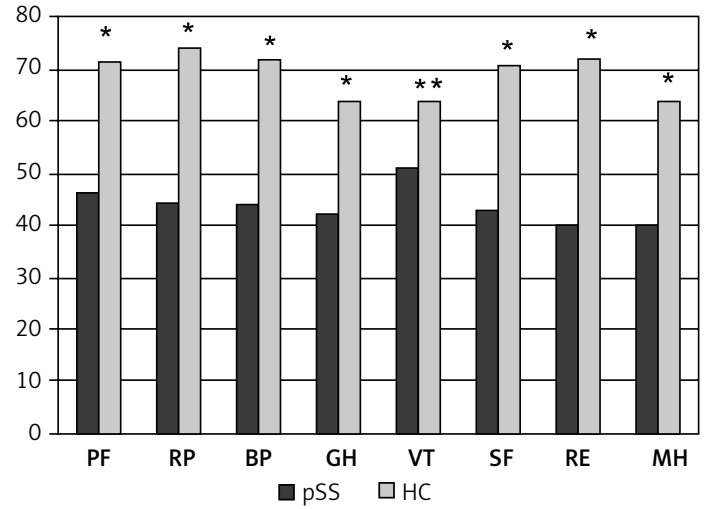

Figure 1. SF-36 subscale scores of pSS patients and $\mathrm{HCS}$

$P F$ - physical functioning, $R P$ - role-physical, $B P$ - bodily pain, GH - general health, VT - vitality, SF - social functioning, $R E$ - role-emotional, $M H$ - mental health; ${ }^{*} p<0.001,{ }^{* *} p=0.006$

SF-36 scales with the exception of VT. ESSPRI was an independent determinant of $\mathrm{BP}, \mathrm{GH}, \mathrm{MH}$ and PCS. Depression, anxiety, and fatigue were significantly correlated with four or more scales of the SF-36.

\section{Discussion}

In order to increase treatment adherence and obtain a better outcome, the evaluation of health quality is important in chronic diseases [27, 28]. The results of this study showed that all domains of the SF-36, particularly RP and role-emotional, were impaired in pSS patients compared with the age- and gender-matched healthy controls. These results are in agreement with previous studies $[10,13,29-36]$. ESSDAI and ESSPRI outcome measures were significantly correlated with all domains of SF-36 (except MH for ESSPRI) and fatigue. In addition, ESSDAI was positively correlated with anxiety and depression scores. Lendrem et al. also reported that higher scores on the ESSDAI and ESSPRI were associated with poorer health states [19]. In another study which assessed the quality of life using the SF-36, Cho et al. reported that $\mathrm{pSS}$ patients with low HRQOL had higher ESSPRI scores and ESSPRI scores were associated with all the SF-36 scales. In contrast to the current study, ESSDAl in that study was not associated with any scales of the SF-36 [20].

Fatigue is an important symptom which has been reported to be related to worsening HRQOL in pSS $[4,6,11]$. In the current study the fatigue score of PSS patients was significantly higher than that of the control group and was positively correlated with anxiety, depression, ESSDAI and ESSPRI scores. Similarly, another study reported that depression was associated with and partially accounted for fatigue in PSS patients [6]. In addition, Barendregt et al. and Bax et al. revealed that 


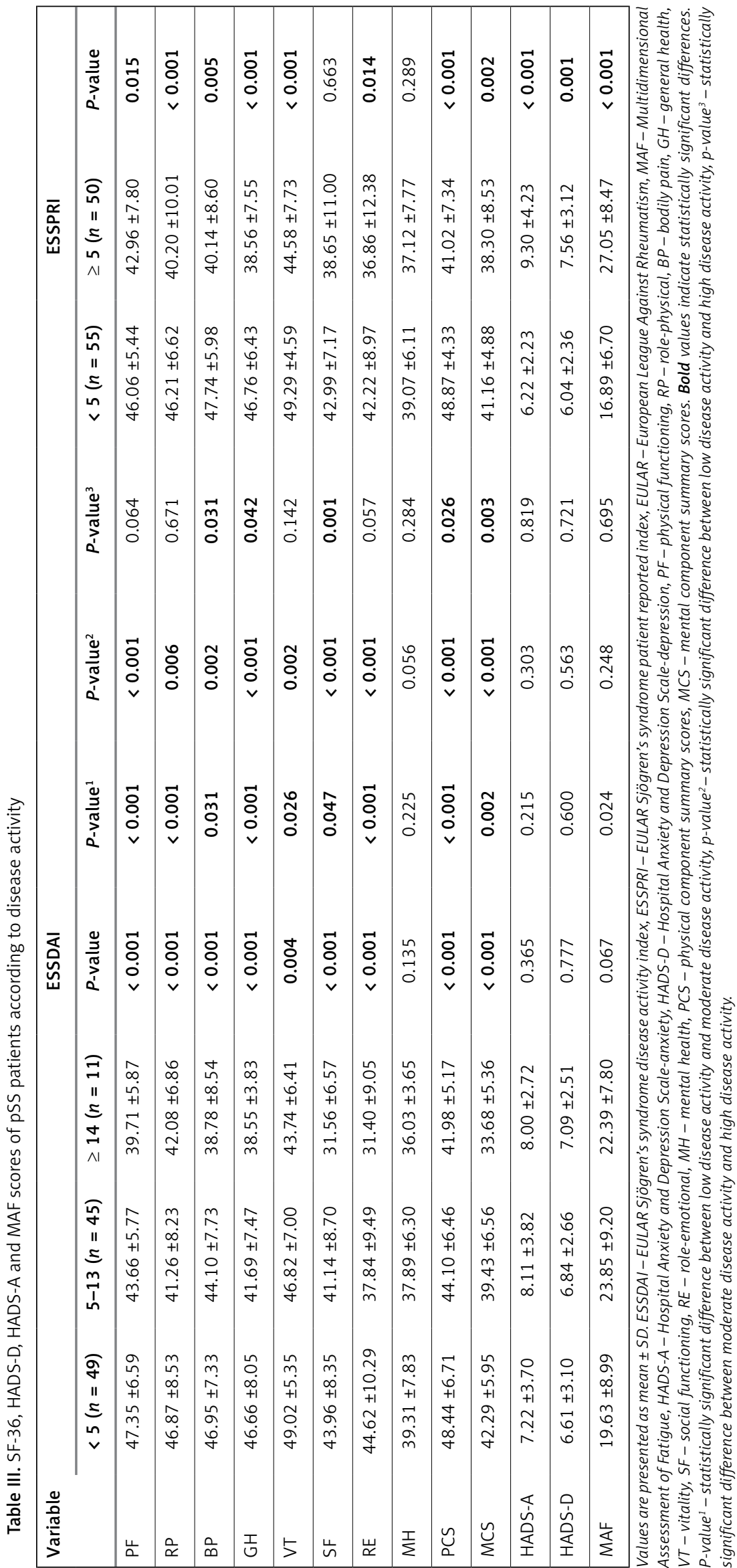


depression was the most relevant cause of fatigue in pSS patients $[4,37]$. In the current study, fatigue was a significant determinant of RP, GH, VT and PCS scores.

Likewise, the prevalence of depression and anxiety was higher in the pSS group. Previous studies have reported that patients with pSS appear to be at increased risk for clinical depression and anxiety, and this psychological disorder can impair quality of life $[5,12,38,39]$. In the current study, the anxiety score was positively correlated with depression, fatigue and ESSPRI scores. Multivariate linear regression analysis showed that anxiety had a negative impact on PF, GH, SF, RE and $\mathrm{MH}$ and depression had a negative impact on RP, BP, VT, RE, PCS and MCS.

Multivariate analyses have revealed that the factors most strongly associated with HRQOL impairment were pain, depression, anxiety, fatigue and ESSPRI [10, 20, 36, 40, 41]. Similarly, in this study, depression, fatigue and ESSDAI were predictors of worse health quality. Unlike other studies, the results of the current study showed that ESSDAI was a predictor for reduced HRQOL $[20,41]$. The pSS patients had a higher mean ESSDAl of 6.56 compared to 3.03 in a study by Cho et al., which was unable to provide conclusive information about the impact of systemic activity [20].

There were several limitations of this study. No evaluation was made of the effect of socio-economic status, education, the impact of medication, drug compliance, auto-antibodies, salivary gland biopsy score, vaginal dryness of women
Table IV. Bivariate Pearson correlation analysis of pSS patients between EULAR Sjögren's syndrome outcome measures and MAF, HADS-A, HADS-D snf SF-36 scores

\begin{tabular}{|lcccc|}
\hline Parameter & \multicolumn{2}{c}{ ESSDAl } & \multicolumn{2}{c|}{ ESSPRI } \\
\cline { 2 - 5 } & $r$ & $P$-value & $r$ & $P$-value \\
\hline PF & -0.435 & $<0.001$ & -0.336 & $<0.001$ \\
\hline RP & -0.296 & 0.001 & -0.396 & $<0.001$ \\
\hline BP & -0.361 & $<0.001$ & -0.531 & $<0.001$ \\
\hline GH & -0.328 & $<0.001$ & -0.687 & $<0.001$ \\
\hline VT & -0.247 & $<0.001$ & -0.436 & $<0.001$ \\
\hline SF & -0.474 & $<0.001$ & -0.271 & 0.002 \\
\hline RE & -0.484 & $<0.001$ & -0.347 & $<0.001$ \\
\hline MH & -0.245 & 0.005 & NS & \\
\hline PCS & -0.327 & $<0.001$ & -0.692 & $<0.001$ \\
\hline MCS & -0.502 & $<0.001$ & -0.263 & 0.002 \\
\hline MAF & 0.026 & 0.003 & 0.805 & $<0.001$ \\
\hline HADS-A & NS & & 0.585 & $<0.001$ \\
\hline HADS-D & NS & & 0.494 & $<0.001$ \\
\hline
\end{tabular}

ESSDAI - EULAR Sjögren's syndrome disease activity index, ESSPRI - EULAR Sjögren's syndrome patient reported index, EULAR European League Against Rheumatism, MAF - Multidimensional Assessment of Fatigue, HADS-A - Hospital Anxiety and Depression Scale-anxiety, HADS-D - Hospital Anxiety and Depression Scaledepression, $P F-$ physical functioning, $R P$-role-physical, $B P$ - bodily pain, GH - general health, VT - vitality, SF - social functioning, $R E$-role-emotional, $M H$ - mental health, $P C S$ - physical component summary scores, MCS - mental component summary scores, NS - not significant.

Table V. Standard regression coefficients ( $\beta$ ) on multiple linear regression analysis for SF-36 scores

\begin{tabular}{|c|c|c|c|c|c|c|c|c|c|c|}
\hline Parameter & PF & RP & BP & $\mathrm{GH}$ & VT & SF & RE & $\mathrm{MH}$ & PCS & MCS \\
\hline HADS-A & $\begin{array}{l}-0.753 \\
(-1.029 \\
-0.477 \\
<0.001)\end{array}$ & & & $\begin{array}{c}-0.458 \\
(-0.797 \\
-0.118 \\
0.009)\end{array}$ & & $\begin{array}{l}-0.718 \\
(-1.109 \\
-0.327 \\
<0.001)\end{array}$ & $\begin{array}{c}-0.529 \\
(-1.140 \\
-0.044 ; \\
0.035)\end{array}$ & $\begin{array}{l}-0.967 \\
(-1.346 \\
-0.588 \\
<0.001)\end{array}$ & & \\
\hline HADS-D & & $\begin{array}{c}-0.932 \\
(-1.486 \\
-0.389 \\
0.001)\end{array}$ & $\begin{array}{c}-0.662 \\
(-1.149 \\
-0.175 \\
0.008)\end{array}$ & & $\begin{array}{c}-0.607 \\
(-1.013 \\
-0.200 \\
0.004)\end{array}$ & & $\begin{array}{c}-1.029 \\
(-1.729 \\
-0.328 \\
0.004)\end{array}$ & & $\begin{array}{c}-0.570 \\
(-0.919 \\
-0.221 \\
0.002)\end{array}$ & $\begin{array}{l}-0.738 \\
(-1.004 \\
-0.472 \\
<0.001)\end{array}$ \\
\hline MAF & & $\begin{array}{c}-0.217 \\
(-0.378 \\
-0.056 \\
0.009)\end{array}$ & & $\begin{array}{c}-0.273 \\
(-0.441 \\
-0.104 \\
0.002)\end{array}$ & $\begin{array}{l}-0.256 \\
(-0.370 \\
-0.142 \\
<0.001)\end{array}$ & & & & $\begin{array}{c}-0.215 \\
(-0.358 \\
-0.072 \\
0.004)\end{array}$ & \\
\hline ESSDAI & $\begin{array}{l}-0.505 \\
(-0.701 \\
-0.309 \\
<0.001)\end{array}$ & $\begin{array}{c}-0.381 \\
(-0.652 \\
-0.110 \\
0.006)\end{array}$ & $\begin{array}{c}-0.394 \\
(-0.639 \\
-0.150 \\
0.002)\end{array}$ & $\begin{array}{c}-0.210 \\
(-0.410 \\
-0.009 \\
0.041)\end{array}$ & & $\begin{array}{l}-0.803 \\
(-1.080 \\
-0.525 \\
<0.001)\end{array}$ & $\begin{array}{l}-0.963 \\
(-1.268 \\
-0.658 \\
<0.001)\end{array}$ & $\begin{array}{c}-0.335 \\
(-0.565 \\
-0.106 \\
0.005)\end{array}$ & $\begin{array}{c}-0.202 \\
(-0.373 \\
-0.030 \\
0.022)\end{array}$ & $\begin{array}{l}-0.604 \\
(-0.793 \\
-0.415 ; \\
<0.001)\end{array}$ \\
\hline ESSPRI & & & $\begin{array}{l}-1.268 \\
(-1.895 \\
-0.642 \\
<0.001)\end{array}$ & $\begin{array}{c}-0.968 \\
(-1.718 \\
-0.217 \\
0.012)\end{array}$ & & & & $\begin{array}{c}0.714 \\
(0.091 \\
1.338 \\
0.025)\end{array}$ & $\begin{array}{c}-0.930 \\
(-1.1558 \\
-0.301 \\
0.004)\end{array}$ & \\
\hline
\end{tabular}

$5 \%$ and $95 \% \mathrm{Cl}$ and $p$-values are presented in parentheses. 
and objective dryness measurements. Laboratory markers such as HSP90a, which may signal fatigue in chronic inflammation and has no direct effect on the depressive state, may be used to evaluate fatigue objectively [42]. Due to the cross-sectional design of the study, the relationship between disease activity, depression, anxiety, fatigue and quality of life remains unclear.

In conclusion, the results of this study showed that the HRQOL of pSS patients was impaired compared to the age- and gender-matched healthy control group and patients with higher disease activity scores had worse HRQOL scores. ESSDAI was negatively correlated with SF-36 scores and positively with MAF. ESSPRI was negatively correlated with SF scores except for mental health and was positively correlated with MAF, HADS-A and HADS-D. Anxiety, depression, fatigue, ESSDAI and ESSPRI were associated with the most SF-36 subscales. Worse quality of life and associated factors should be taken into account when managing patients with pSS. Primary end points for therapeutic trials should include the cardinal primary SS symptoms such as anxiety, depression, and fatigue.

\section{Conflict of interest}

The authors declare no conflict of interest.

\section{References}

1. Fox RI. Sjogren's syndrome. Lancet 2005; 366: 321-31.

2. Qin B, Wang J, Yang Z, et al. Epidemiology of primary Sjogren's syndrome: a systematic review and metaanalysis. Ann Rheum Dis 2015; 74: 1983-9.

3. Luciano N, Valentini V, Calabro A, et al. One year in review 2015: Sjogren's syndrome. Clin Exp Rheumatol 2015; 33: 259-71.

4. Barendregt PJ, Visser MR, Smets EM, et al. Fatigue in primary Sjogren's syndrome. Ann Rheum Dis 1998; 57: 291-5.

5. Shen CC, Yang AC, Kuo BI, Tsai SJ. Risk of psychiatric disorders following primary Sjogren syndrome: a nationwide population-based retrospective cohort study. J Rheumatol 2015; 42: 1203-8.

6. Segal B, Thomas W, Rogers T, et al. Prevalence, severity, and predictors of fatigue in subjects with primary Sjogren's syndrome. Arthritis Rheum 2008; 59: 1780-7.

7. Karageorgas T, Fragioudaki S, Nezos A, Karaiskos D, Moutsopoulos HM, Mavragani CP. Fatigue in primary Sjogren's syndrome: clinical, laboratory, psychometric, and biologic associations. Arthritis Care Res (Hoboken) 2016; 68: 123-31.

8. Westhoff G, Dorner T, Zink A. Fatigue and depression predict physician visits and work disability in women with primary Sjogren's syndrome: results from a cohort study. Rheumatology (Oxford) 2012; 51: 262-9.

9. Xiang YJ, Dai SM. Prevalence of rheumatic diseases and disability in China. Rheumatol Int 2009; 29: 481-90.

10. Meijer JM, Meiners PM, Huddleston Slater JJ, et al. Health-related quality of life, employment and disability in patients with Sjogren's syndrome. Rheumatology (Oxford) 2009; 48: 1077-82.
11. Strombeck B, Ekdahl C, Manthorpe R, Wikstrom I, Jacobsson L. Health-related quality of life in primary Sjogren's syndrome, rheumatoid arthritis and fibromyalgia compared to normal population data using SF-36. Scand J Rheumatol 2000; 29: 20-8.

12. Inal V, Kitapcioglu G, Karabulut G, Keser G, Kabasakal Y. Evaluation of quality of life in relation to anxiety and depression in primary Sjogren's syndrome. Mod Rheumatol 2010; 20: 588-97.

13. Zhang Q, Wang X, Chen H, Shen B. Sjogren's syndrome is associated with negatively variable impacts on domains of health-related quality of life: evidence from Short Form 36 questionnaire and a meta-analysis. Patient Prefer Adherence 2017; 11: 905-11.

14. Seror R, Ravaud P, Bowman SJ, et al. EULAR Sjogren's syndrome disease activity index: development of a consensus systemic disease activity index for primary Sjogren's syndrome. Ann Rheum Dis 2010; 69: 1103-9.

15. Seror R, Ravaud P, Mariette X, et al. EULAR Sjogren's Syndrome Patient Reported Index (ESSPRI): development of a consensus patient index for primary Sjogren's syndrome. Ann Rheum Dis 2011; 70: 968-72.

16. Seror R, Theander E, Brun JG, et al. Validation of EULAR primary Sjogren's syndrome disease activity (ESSDAI) and patient indexes (ESSPRI). Ann Rheum Dis 2015; 74: 859-66.

17. Bowman SJ, Booth DA, Platts RG, Group UKSsI. Measurement of fatigue and discomfort in primary Sjogren's syndrome using a new questionnaire tool. Rheumatology (Oxford) 2004; 43: 758-64.

18. McMillan AS, Leung KC, Leung WK, Wong MC, Lau CS, Mok TM. Impact of Sjogren's syndrome on oral healthrelated quality of life in southern Chinese. J Oral Rehabil 2004; 31: 653-9.

19. Lendrem D, Mitchell S, McMeekin P, et al. Do the EULAR Sjogren's syndrome outcome measures correlate with health status in primary Sjogren's syndrome? Rheumatology (Oxford) 2015; 54: 655-9.

20. Cho HJ, Yoo JJ, Yun CY, et al. The EULAR Sjogren's syndrome patient reported index as an independent determinant of health-related quality of life in primary Sjogren's syndrome patients: in comparison with nonSjogren's sicca patients. Rheumatology (Oxford) 2013; 52: 2208-17.

21. Vitali C, Bombardieri S, Jonsson R, et al. Classification criteria for Sjogren's syndrome: a revised version of the European criteria proposed by the American-European Consensus Group. Ann Rheum Dis 2002; 61: 554-8.

22. Neuberger GB. Measures of fatigue: the Fatigue Questionnaire, Fatigue Severity Scale, Multidimensional Assessment of Fatigue Scale, and Short Form-36 Vitality (Energy/Fatigue) Subscale of the Short Form Health Survey. Arthritis Care Res 2003; 49 (Suppl 5): S175-83.

23. Zigmond AS, Snaith RP. The hospital anxiety and depression scale. Acta Psychiatr Scand 1983; 67: 361-70.

24. Pinar R. Reliability and construct validity of the SF-36 in Turkish cancer patients. Qual Life Res 2005; 14: 259-64.

25. Ware JE Jr, Sherbourne CD. The MOS 36-item short-form health survey (SF-36). I. Conceptual framework and item selection. Med Care 1992; 30: 473-83.

26. Seror R, Bootsma H, Saraux A, et al. Defining disease activity states and clinically meaningful improvement in primary Sjogren's syndrome with EULAR primary Sjogren's syndrome disease activity (ESSDAI) and patient-reported indexes (ESSPRI). Ann Rheum Dis 2016; 75: 382-9.

27. Nowicki A, Farbicka P, Krajnik M. Late palliative care of patients with lung cancer may have a limited effect on 
quality of life - a pilot observational study. Arch Med Sci Civil Dis 2016; 1: e1-9.

28. Soponaru C, Bojian A, lorga M. Stress, coping mechanisms and quality of life in hemodialysis patients. Arch Med Sci Civili Dis 2016; 1: e16-23.

29. Stewart CM, Berg KM, Cha S, Reeves WH. Salivary dysfunction and quality of life in Sjogren syndrome: a critical oral-systemic connection. J Am Dent Assoc 2008; 139: 291-9; quiz 358-9.

30. Champey J, Corruble E, Gottenberg JE, et al. Quality of life and psychological status in patients with primary Sjogren's syndrome and sicca symptoms without autoimmune features. Arthritis Rheum 2006; 55: 451-7.

31. Belenguer R, Ramos-Casals M, Brito-Zeron P, et al. Influence of clinical and immunological parameters on the health-related quality of life of patients with primary Sjogren's syndrome. Clin Exp Rheumatol 2005; 23: 351-6.

32. Rajagopalan K, Abetz L, Mertzanis P, et al. Comparing the discriminative validity of two generic and one disease-specific health-related quality of life measures in a sample of patients with dry eye. Value Health 2005; 8: 168-74.

33. Kocer B, Tezcan ME, Batur HZ, et al. Cognition, depression, fatigue, and quality of life in primary Sjogren's syndrome: correlations. Brain Behav 2016; 6: e00586.

34. Milin M, Cornec D, Chastaing M, et al. Sicca symptoms are associated with similar fatigue, anxiety, depression, and quality-of-life impairments in patients with and without primary Sjogren's syndrome. Joint Bone Spine 2016; 83: 681-5.

35. Dassouki T, Benatti FB, Pinto AJ, et al. Objectively measured physical activity and its influence on physical capacity and clinical parameters in patients with primary Sjogren's syndrome. Lupus 2017; 26: 690-7.

36. Lee J, Koh JH, Kwok SK, Park SH. The EULAR Sjogren's Syndrome Patient-Reported Index is an independent determinant of health-related utility values of Korean patients with primary Sjogren's syndrome. Clin Exp Rheumatol 2016; 34: 663-7.

37. Bax HI, Vriesendorp TM, Kallenberg CG, Kalk WW. Fatigue and immune activity in Sjogren's syndrome. Ann Rheum Dis 2002; 61: 284.

38. Valtysdottir ST, Gudbjornsson B, Lindqvist U, Hallgren R, Hetta J. Anxiety and depression in patients with primary Sjogren's syndrome. J Rheumatol 2000; 27: 165-9.

39. Stevenson HA, Jones ME, Rostron JL, Longman LP, Field EA. UK patients with primary Sjogren's syndrome are at increased risk from clinical depression. Gerodontology 2004; 21: 141-5.

40. Segal B, Bowman SJ, Fox PC, et al. Primary Sjogren's syndrome: health experiences and predictors of health quality among patients in the United States. Health Qual Life Outcomes 2009; 7: 46.

41. Cornec D, Devauchelle-Pensec V, Mariette X, Jet al. Severe Health-Related Quality of life impairment in active primary Sjogren's syndrome and patient-reported outcomes: data from a large therapeutic trial. Arthritis Care Res (Hoboken) 2017; 69: 528-35.

42. Bardsen K, Nilsen MM, Kvaloy JT, Norheim KB, Jonsson G, Omdal R. Heat shock proteins and chronic fatigue in primary Sjogren's syndrome. Innate Immun 2016; 22 : 162-7. 